\title{
High-cycle fatigue bending strength of rapidly solidified and plastic consolidated RS442 aluminium alloy
}

\author{
Maciej Motyka - Tomasz Tokarski • \\ Waldemar Ziaja $\cdot$ Henryk Dybiec $\cdot$ Jan Sieniawski
}

Received: 19 November 2012/ Accepted: 12 February 2013/Published online: 22 February 2013

(C) The Author(s) 2013. This article is published with open access at Springerlink.com

\begin{abstract}
Grain refinement in metallic materials down to submicro and nano scale results in improvement of mechanical properties. However, increase in strength under static load is not always accompanied by improved fatigue behaviour. In the current studies microstructure and mechanical properties of the submicrocrystalline RS442 aluminium alloy (chemical composition corresponds to conventional 442 cast alloy) were investigated. The alloy was subjected to rapid solidification followed by the extrusion process (variant 1 ) and additional annealing at $450{ }^{\circ} \mathrm{C}$ (variant 2 ). Rapidly solidified alloy was also consolidated with addition of graphite (variant 3 ). As the reference material conventionally cast and extruded alloy was also tested (variant 4). For all material variants strength properties were tested in static tensile test and high-cycle stress-controlled fatigue bending tests. It was found that rapid solidification and plastic consolidations led to increase of static mechanical properties of 442 alloy but reduced its fatigue strength.
\end{abstract}

\section{Introduction}

Grain refinement has been applied as an effective method of improving the strength of crystalline materials for many years. Development of severe plastic deformation techniques enabled grain size reduction down to submicro or even nano scale $[1,2]$. The so-called ultrafine-grained materials

M. Motyka $(\bowtie) \cdot$ W. Ziaja $\cdot$ J. Sieniawski

Department of Materials Science, Rzeszow University of

Technology, ul. Powst. Warszawy 12, 35-959 Rzeszow, Poland

e-mail: motyka@prz.edu.pl

T. Tokarski $\cdot$ H. Dybiec

Faculty of Non-Ferrous Metals, AGH University of Science and

Technology, A. Mickiewicza 30 Ave, 30-059 Krakow, Poland
(UFG) — having the grain size in the range of $100 \mathrm{~nm}-1 \mu \mathrm{m}-$ and nanocrystalline materials (NC) - average grain size below $100 \mathrm{~nm}$ - exhibit exceptional properties compared to conventional polycrystalline materials [1, 3, 4]. It may concern either mechanical or physical properties, for example increased strength/hardness, improved toughness, reduced elastic modulus and ductility, enhanced diffusivity, higher specific heat and enhanced thermal expansion coefficient. These advantageous changes in static properties may be accompanied by decrease of fatigue life with decreasing grain size $[5,6]$. It can pose a problem in case of aluminium alloys for which fatigue properties are often critical due to their widespread use in aerospace and automotive industries. Despite extensive research carried out on that subject in last years the fatigue behaviour of UFG aluminium alloys is far from being fully understood [7-10]. Important reason for that is complexity of the influence of microstructure, mainly grain size, on the mechanisms of cyclic deformation, fatigue crack initiation and propagation. The aim of current study was to investigate the effect of processing route on the microstructure, mechanical properties and fatigue properties of the RS442 alloy obtained by rapid solidification and plastic consolidation, which is a frequently used technique to manufacture UFG aluminium alloys [11]. As the grain refinement has usually adverse influence on the material resistance to fatigue crack nucleation and propagation [12] in current tests notched fatigue specimens were used to suppress the crack initiation stage and examine the effect of processing conditions and alloy microstructure on crack propagation behaviour.

\section{Materials and experiment}

The aluminium alloy $\mathrm{RS} 442(\mathrm{Si}, 12.5 ; \mathrm{Fe}, 5 ; \mathrm{Cu}, 3.5 ; \mathrm{Mg}$, $1 ; \mathrm{Zr}, 0.2$; Ti, $0.1 \mathrm{wt} \%$; Al—balance) after industrial 


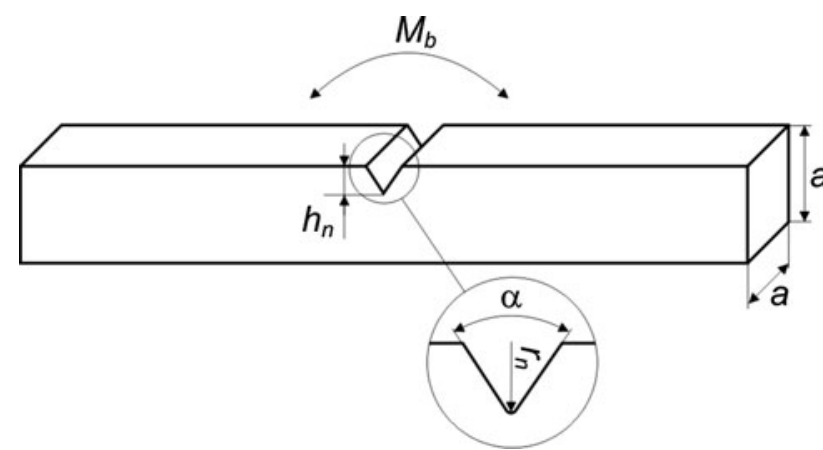

Fig. 1 A schematic view of the notched specimen used for bending fatigue tests

process of the rapid solidification (RS) by melt spinning method was subject to investigation. Rapidly solidified ribbons were chopped to flakes form and then were compacted by cold pressing at about $600 \mathrm{MPa}$ pressure to billet of $38 \mathrm{~mm}$ diameter and $35 \mathrm{~mm}$ length. The billets were degassed at temperature of $400{ }^{\circ} \mathrm{C}$ for $20 \mathrm{~min}$ and then directly placed into extrusion stand container at the same temperature. Plastic consolidation by hot extrusion was performed at degassing temperature at the piston rate $0.5 \mathrm{~mm} / \mathrm{s}$ and extrusion ratio $\lambda=25$. As a result bulk rods of $8 \mathrm{~mm}$ diameter $\phi$ were produced (variant 1). Some rods were annealed at $450{ }^{\circ} \mathrm{C} / 2 \mathrm{~h}$ (variant 2). Rapidly solidified flakes were also mixed with graphite (about $3 \mathrm{wt} \%$ ) and then consolidated and extruded to the form of rods $\phi$ $11.5 \mathrm{~mm}$ in diameter (variant 3). As a reference 442 alloy was examined in the cast and extruded form (variant 4 ).

The microstructure of the material was examined by scanning (Hitachi SU70) and transmission (Jeol 2010ARP) electron microscopy techniques. Mechanical properties
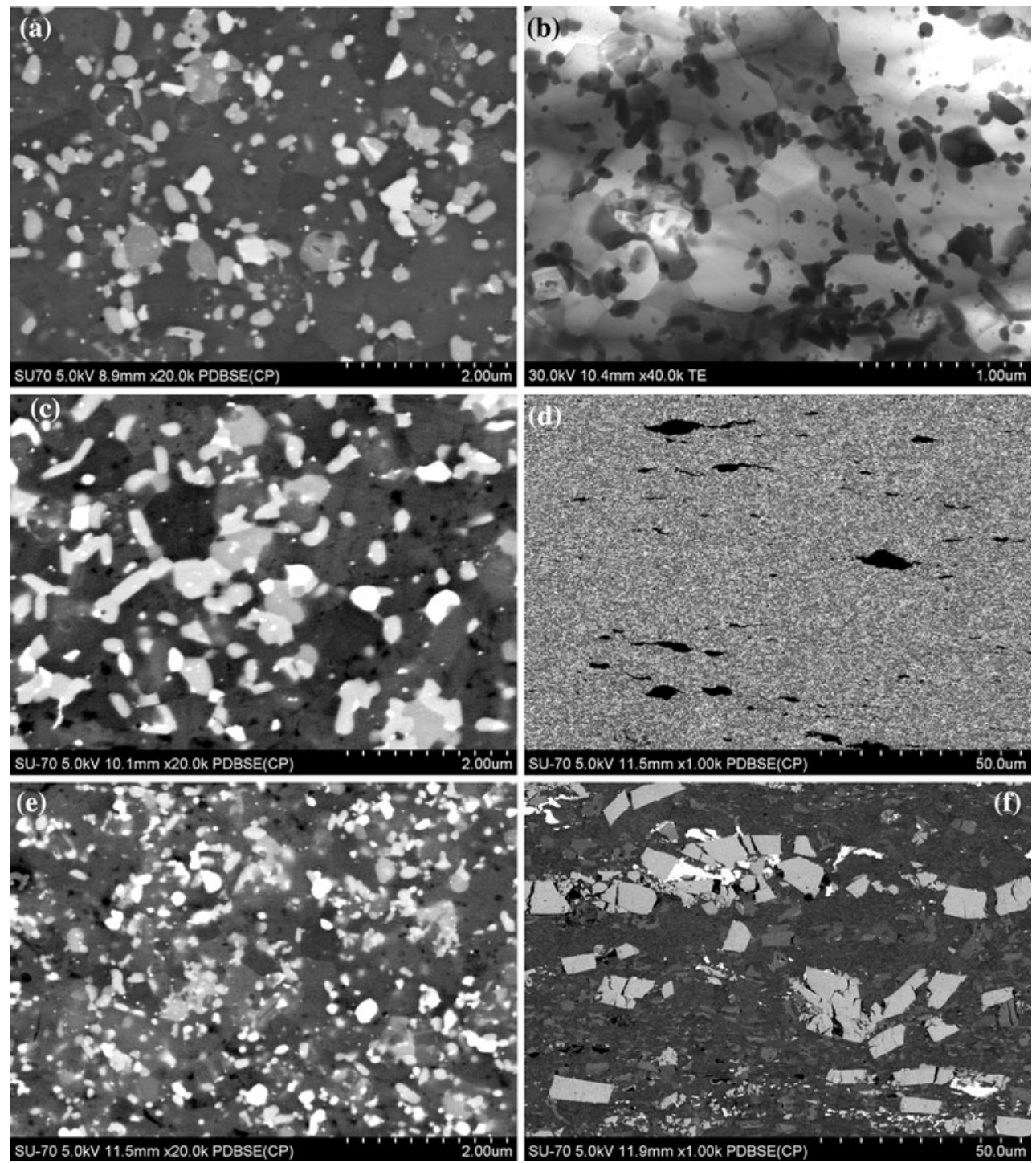

Fig. 2 Microstructure of RS442 alloy (SEM BSE): RS + plastic consolidation—variant 1 (a, b-TEM); RS + plastic consolidation + annealing—variant $2(\mathbf{c}) ; \mathrm{RS}+$ plastic consolidation with graphite (RS442 + C)—variant $3(\mathbf{d}, \mathbf{e})$ and cast and extruded—variant $4(\mathbf{f})$ 
Table 1 Mechanical properties of RS442 aluminium alloy

\begin{tabular}{lllllll}
\hline Variant & $\begin{array}{l}\text { Yield strength } \sigma_{0.2}, \\
(\mathrm{MPa})\end{array}$ & $\begin{array}{l}\text { Stand. dev. of } \sigma_{0.2}, \\
(\mathrm{MPa})\end{array}$ & $\begin{array}{l}\text { Tensile strength } \sigma_{\mathrm{m}}, \\
(\mathrm{MPa})\end{array}$ & $\begin{array}{l}\text { Stand. dev. of } \sigma_{\mathrm{m}}, \\
(\mathrm{MPa})\end{array}$ & $\begin{array}{l}\text { Elongation } A_{100}, \\
(\%)\end{array}$ & $\begin{array}{l}\text { Stand. dev. of } A_{100}, \\
(\%)\end{array}$ \\
\hline 1 & 410 & 3.9 & 500 & 6.0 & 1.5 & 0.25 \\
2 & 420 & 4.3 & 555 & 6.3 & 2.0 & 0.26 \\
3 & 325 & 7.3 & 380 & 9.1 & 0.7 & 0.28 \\
4 & 170 & 3.7 & 270 & 4.9 & 1.8 & 0.19 \\
\hline
\end{tabular}

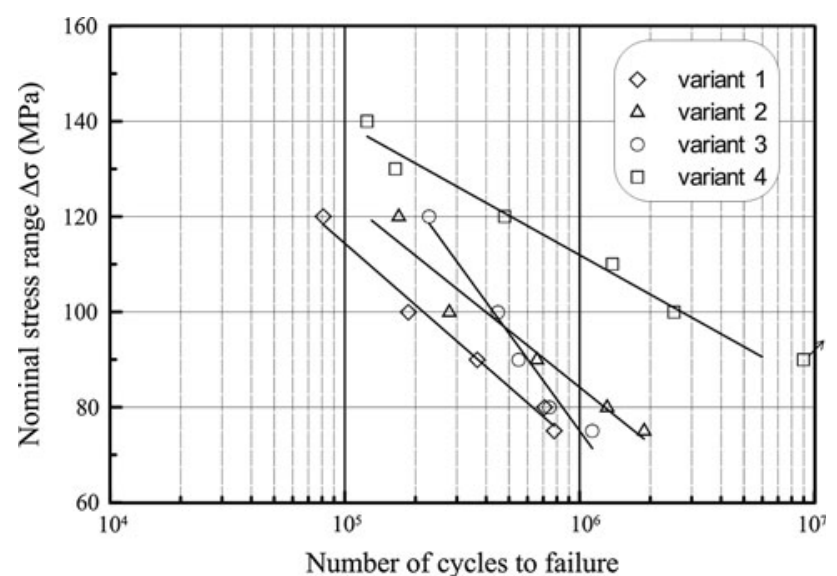

Fig. 3 S-N diagram for RS442-four-point bending test at $R=0$

have been determined by tensile tests using universal testing machine Zwick Z50. The $0.2 \%$ offset yield strength $\left(\sigma_{0.2}\right)$, ultimate tensile strength $\left(\sigma_{\mathrm{m}}\right)$ and elongation $\left(A_{100}\right)$ have been measured on 4 samples and mean values of the above parameters have been determined.

Stress-controlled four-point bending fatigue tests on notched specimens were carried out to assess fatigue properties of the UFG aluminium alloy. Fatigue tests were carried out using Cracktronic resonant testing machine from RUMUL at the stress ratio $R=0$. Rectangular cross section specimens with V-notch were tested. Basic dimensions of the specimen were $a=5.5 \mathrm{~mm}$, $r_{\mathrm{n}}=0.28 \mathrm{~mm}, h_{\mathrm{n}}=0.8 \mathrm{~mm}$ and $\alpha=60^{\circ}$ (Fig. 1). The notch was machined using electro-erosion machine. The theoretical stress concentration factor $K_{\mathrm{t}}$ for the notched specimen was equal to 2.3 according to Peterson's tables [13]. The tests were performed at the resonant frequency which was about $45 \mathrm{~Hz}$. Fracture surfaces were examined using scanning electron microscope Hitachi S 3400NII.

\section{Results and discussion}

Detailed phase identification in 442 aluminium alloy is difficult because of its complex chemical composition. BSE detection allowed to determine that the microstructure
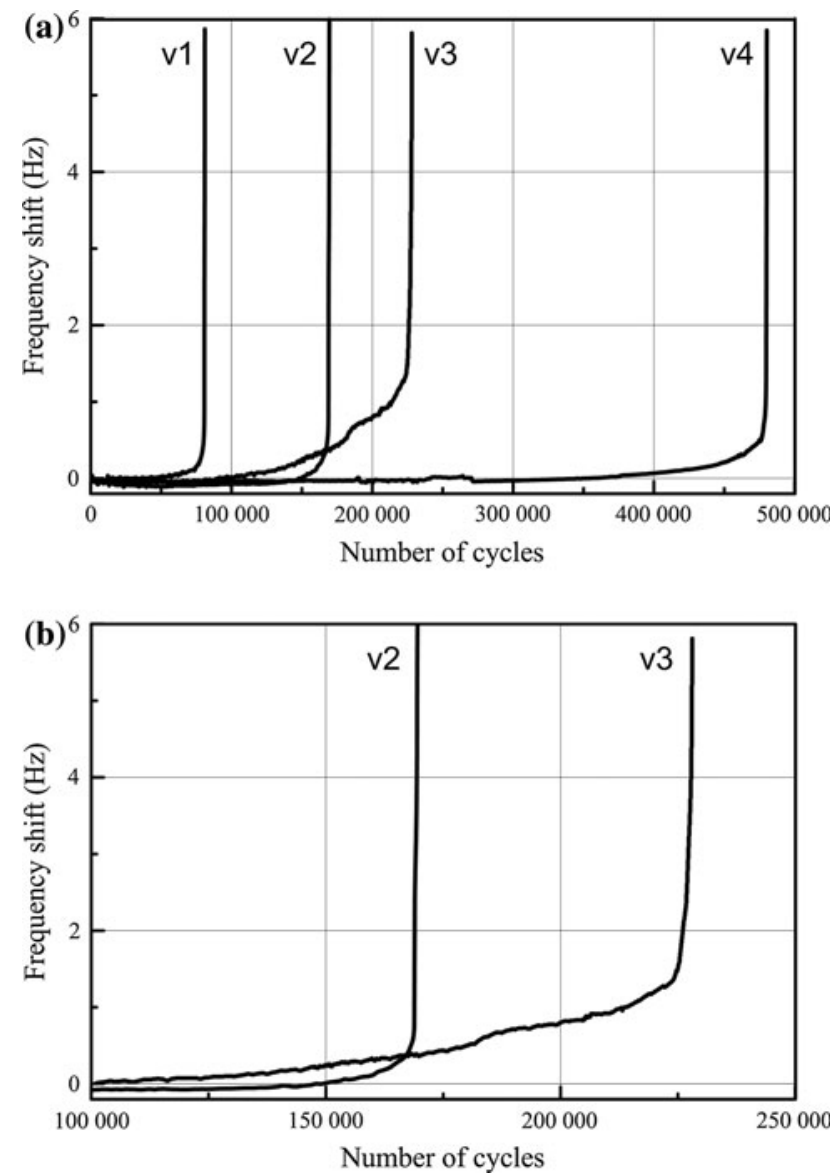

Fig. 4 Variation of resonant frequency of the specimen-grip system caused by fatigue crack growth at the stress range $\Delta \sigma=120 \mathrm{MPa}$

is composed of precipitates of intermetallic phases containing heavy elements, mainly $\mathrm{Fe}, \mathrm{Cu}$ and $\mathrm{Si}$ precipitates in aluminium matrix (Fig. 2a, c, e). Small size of observed phase precludes determination of their chemical composition using SEM methods. In BSE mode precise determination of grain size of the matrix was not possible due to low contrast of grain boundaries. TEM technique was applied to determine the matrix grain size which was found to be about $0.4 \mu \mathrm{m}$ in rapidly solidified and plastic consolidated RS442 alloy (Fig. 2b).

The lack of material discontinuities is an evidence of full consolidation of examined material. Plastic consolidation of 
the rapidly solidified alloy results in a significant increase of the mechanical properties of material comparing to the alloy extruded after conventional casting (Table 1). Tensile strength and yield strength are roughly doubled with no substantially reduced ductility.

Annealing of plastic consolidated RS442 aluminium alloy at $450{ }^{\circ} \mathrm{C}$, which is $50{ }^{\circ} \mathrm{C}$ higher than consolidation temperature, leads to further precipitation of intermetallic phases and coagulation of the precipitates (Fig. 2c). Qualitative microstructure examination allowed to identify grain coarsening compared to consolidated material. In spite of these changes static mechanical properties are still high - with even higher ultimate tensile strength (Table 1). The possible mechanism of this strength improvement may be strengthening by intermetallic phase precipitates which prevails over the softening effect caused by grain growth.

RS442 alloy consolidated with graphite also has finegrained microstructure (Fig. 2d, e). Distribution of graphite precipitates is non-uniform. Larger ones are significantly elongated in the deformation direction caused by plastic consolidation. These non-metallic inclusions cause reduction of strength properties of the alloy, which are still higher than in conventional material (Table 1).

Microstructure of reference 442 cast and extruded alloy consists of coarse precipitates of phases containing $\mathrm{Fe}, \mathrm{Cu}$ and Si (BSE detection) (Fig. 2f). Many coarse precipitates undergo fragmentation during extrusion which is the result of their brittleness.
Fatigue life of all variants of the consolidated, ultrafinegrained alloy is significantly lower at the stress level applied, compared to conventionally cast and extruded alloy (variant 4) (Fig. 3), despite its lowest static strength properties. It may be attributed to the increased plasticity and higher susceptibility to strain hardening and the combined effect of these factors on the dominant crack growth mechanisms. Another factor is the level of crack path tortuosity which diminishes with decrease of grain size. It results in more significant roughness-induced crack closure and crack deflections in conventional alloy.

The alloy with graphite shows slightly different fatigue behaviour than other alloys. Its fatigue life drops slowly with increase of the stress range and at the higher stresses it shows longer life than the consolidated alloys without graphite. Also the fatigue crack growth character is somewhat different which can be correlated qualitatively with resonant frequency shift caused by crack propagation and change of the specimen stiffness (Fig. 4). The resonant frequency decreases slowly over the large number of cycles (almost half of the total number of cycles to failure) while in other alloys these changes occur more rapidly over the last $10-15 \%$ cycles of the test.

Examination of the fracture surfaces after fatigue tests revealed their similar character for all variants of plastic consolidated alloys. The presence of the features of the size comparable approximately with the grain size after consolidation indicates intergranular cracking (Fig. 5a-c).
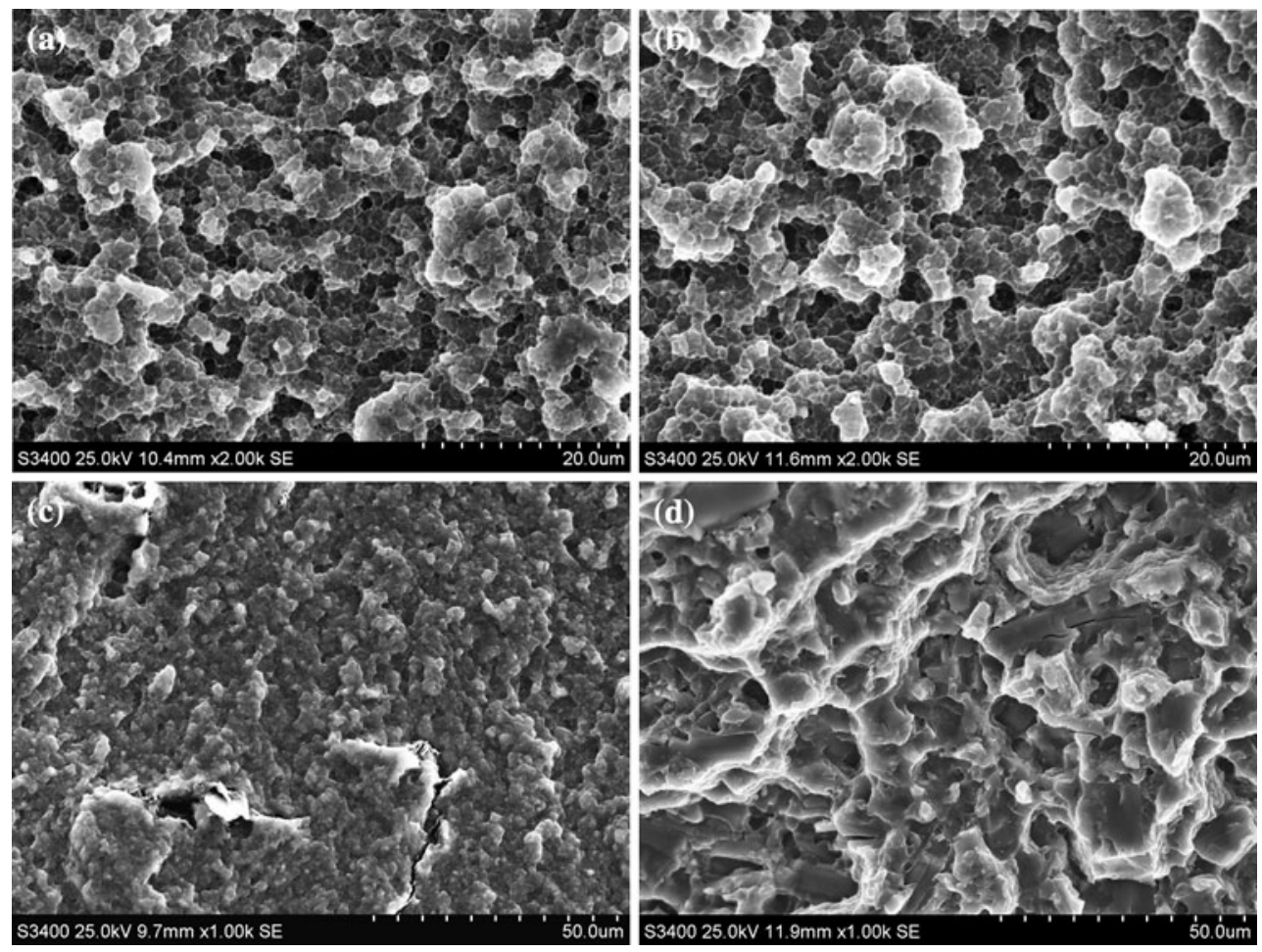

Fig. 5 Fatigue fracture surfaces in the area of stable crack growth for RS442 alloy—variants: 1 (a), 2 (b), 3 (c) and 4 (d) 
Relative softening of the grain boundaries formed during plastic consolidation seems to be natural effect of lack of full cohesion, although discontinuities on the grain boundaries were not identified during microstructure examination. The cohesion is high enough to guarantee high static mechanical properties of material. The imperfection of grain boundaries may result from separation of some segments of the boundary due to the presence of the oxides formed on the initial free surface of rapidly solidified flakes and their scaling. Generally it may be assumed that intergranular character of fracture surfaces results from accumulation of defects in the regions of the most probable strain localization. It justifies hypothesis concerning significant role of near grain boundary areas in plastic deformation process.

In the alloy containing graphite intergranular cracking of the matrix is accompanied by cracking of graphite inclusions (Fig. 5c). It facilitates cracking process but on the other hand leads to more irregular crack path which together can contribute to different character of crack growth rate variations and resonant frequency changes (Fig. 4).

Fatigue fracture surface of cast and extruded alloy shows mixed character with limited ductile fracture areas. Cracking of the intermetallic phases and coarse silicon precipitates took place at which some secondary cracks were observed (Fig. 5d). Higher propensity to local plastic deformation in micro areas and increased crack path tortuosity are considered to be the reason for longer fatigue life of conventional alloy.

\section{Conclusions}

Rapid solidification and plastic consolidation lead to grain refinement and significant increase of static mechanical properties of 442 aluminium alloy.

Fatigue strength of submicrocrystalline RS442 alloy shows little variation depending on the processing route and is lower than conventionally cast and extruded alloy.

Addition of graphite to submicrocrystalline alloy modifies its fatigue behaviour leading to increase in fatigue life for higher stress range values compared to the alloy without graphite. It also changes the fatigue crack growth characteristic.

In the submicrocrystalline alloy intergranular cracking prevailed which can be attributed to lack of full cohesion on the grain boundaries after plastic consolidation.

Better fatigue properties of conventionally cast and extruded alloy can be attributed to higher contribution of ductile cracking which is also reflected on the fracture surfaces.

Acknowledgements Financial support of Structural Funds in the Operational Programme-Innovative Economy (IE OP) financed by the European Regional Development Fund-Project No POIG.01.03.01-00-015/08 (NANOMET) is gratefully acknowledged.

Open Access This article is distributed under the terms of the Creative Commons Attribution License which permits any use, distribution, and reproduction in any medium, provided the original author(s) and the source are credited.

\section{References}

1. Valiev RZ, Islamgaliev RK, Alexandrov IV (2000) Prog Mater Sci 45:103-189

2. Lewandowska M, Kurzydlowski KJ (2008) J Mater Sci 43:7299. doi:10.1007/s10853-008-2810-z

3. Meyers MA, Mishra A, Benson DJ (2006) Prog Mater Sci 51:427-556

4. Bazarnik P, Lewandowska M, Andrzejczuk M, Kurzydlowski KJ (2012) Mater Sci Eng A556:134-139

5. Hanlon T, Tabachnikova ED, Suresh S (2005) Int J Fatigue 27:1147-1158

6. Cavaliere P (2009) J Fatigue 31:1476-1489

7. Garbacz H, Pakiela Z, Kurzydlowski KJ (2010) Rev Adv Mater Sci 25(3):256-260

8. Chung CS, Kim JK, Kim HK, Kim WJ (2002) Mater Sci Eng A337:39-44

9. Estrin Y, Vinogradov A (2010) Int J Fatigue 32:898-907

10. Mughrabi H, Höppel HW, Kautz M (2004) Scr Mater 51:807-812

11. Dybiec H (2008) Submicrocrystalline aluminium alloys. AGH, Cracow (in Polish)

12. Höppel HW, Mughrabi H, Vinogradov A et al (2009) In: Zehetbauer M (ed) Bulk nanostructured materials. Wiley VCH Verlag, Weinheim, pp 481-500

13. Pilkey WD (1997) Peterson's Stress Concentration Factors. Wiley Interscience Publication, New York 